\title{
MULHERES SOLTEIRAS POBRES E A MATERNIDADE NO PÓS-ABOLIÇÃO (SÃO JOSÉ DOS CAMPOS/SP/1888)
}

\section{Sara Carolina Noce Bortoncello' Maria Aparecida Chaves Ribeiro Papali ${ }^{2}$}

Resumo: Este trabalho tem o objetivo de discutir as condições das mulheres pobres, solteiras, e a sua relação com a maternidade no pós-abolição, com base na analise de processos de tutela de órfãos do ano de 1888 , do $2^{\circ}$ Cartório de São José dos Campos, SP, situado no Vale do Paraíba Paulista. Para exemplificar a condição da mulher e a questão da maternidade, foi escolhido um processo que se encontra no Arquivo Público Municipal de São José dos Campos, localizado na caixa de número 746 do $2^{\circ}$ Cartório Cível da cidade. A trajetória de vida dessas mulheres pobres, solteiras, que tentam sobreviver em um mundo sem grandes oportunidades mostra um percurso de luta constante pela sua própria sobrevivência e a de seus filhos no cenário do pós-abolição.

Palavras-chave: Pós-abolição; Mulher pobre; Solteira; Maternidade.

\footnotetext{
1 Universidade do Vale do Paraíba - UNIVAP, Brasil. E-mail: saranocebortoncello@gmail.com.

2 Universidade do Vale do Paraíba - UNIVAP, Brasil. E-mail: papali@univap.br.
} 